\title{
DESIGN AND SIMULATION OF SIERPINSKI CARPET FRACTAL ANTENNA AND COMPARISION OF DIFFERENT FEEDS
}

\author{
S.Ravi ${ }^{1}$, V.Srinivasa Rao ${ }^{2}$ \\ ${ }^{1}$ Dept. of Elect \& Comm. Engineering, GITAM Institute of technology, Visakhapatnam, India \\ ${ }^{2}$ Dept. of Elect \& Comm. Engineering, GITAM Institute of technology, Visakhapatnam, India
}

\begin{abstract}
The rapid growth in wireless communication has led to need of antennas with increased bandwidth, high gain and low profile. In this paper, a multi band microstrip antenna is designed by applying fractal concept to a rectangular microstrip antenna. The antennas properties gain, and return loss, are studied to achieve better performance. The designed antenna is compared for different feeding techniques and the results are analyzed. This antenna is designed and simulated by using HFSS software.
\end{abstract}

Keywords-microstrip; fractal; multiband; feeding techniques.

\section{INTRODUCTION}

Nowadays, in order to face the technological improvement, humankind needs to hold up with the advancement. This advancement has led to the development of cellular devices to provide high-speed and high-quality information exchange between portable devices located anywhere in the world. This brought up many new areas of investigation; the one with main interest for this work is the research of antennas with fractal geometry.

An antenna is a device which is used to transmit or receive electromagnetic waves. The IEEE Standard definitions of terms for antenna (IEEE Std 145-1983) defines the antenna or aerial as "A means for radiating or receiving radio waves" [1]. The microstrip antennas are one type of antennas having advantages like low-profile, amenable to planar and nonplanar surfaces, simple and economical to fabricate using modern printed-circuit technology and mechanically robust.

The main problem of common antennas is that only operate at one or two frequencies, narrowing the number of bands that equipment is capable of supporting. Another issue is the size of a common antenna. Due to the very minimal space that a handset has, setting up more than one antenna is very difficult. To help these problems, the research is focused in fractal shaped antennas [2].

\section{MICROSTRIP ANTENNAS}

Microstrip antennas consist of a metallic patch on a grounded substrate. The metallic patch can take many configurations, rectangular and circular patches are mostly used shapes. Microstrip antennas are increasing in popularity for use in wireless communication because of low profile and easy to fabricate. Therefore, they are extremely compatible for embedded antennas in handheld devices such as cell phones. Some of the advantages of microstrip antennas are,

- Miniature in size and low weight.

- Low profile planar configuration due to which it can be easily mounted.

- Low fabrication cost, so they can be manufactured in large quantity.

- Mechanically tough when mounted on rigid surfaces.

- Can be used for both linear and circular polarization. Microstrip antennas also suffer from some draw backs compared to conventional antennas. Some of the disadvantages are,

- Low power handling capability.

- Narrow band width.

- Extraneous radiations from feeds and junctions.

- Surface wave excitation.

There are several feeding techniques for microstrip antennas like, microstrip feed, inset feed, aperture coupled feed, coaxial probe feed and proximity coupled feed. In this paper, we have designed the antenna with microstrip feed and inset feed techniques.

\section{FRACTAL ANTENNAS}

A fractal is a rough or fragmented geometric shape that can be subdivided in parts, each of which is ( at least approximately) a reduced-size copy of the whole. Fractals are self-similar structures and independent of scale [3]. The fractal term was coined in 1975 by, Benoit B. Mandelbrot who is a French mathematician. Since Mandelbrot work a wide variety of application areas for fractals have been found and studied, an area in particular is fractal electrodynamics. This area combines electromagnetic theory with fractal geometry, this merger results in new radiation patterns, propagation and 
scattering problems. Studies in this area show that fractals have good electromagnetic radiation patterns and advantages over traditional antennas. These advantages are used to face modern wireless communication problems. For example, they can be used as compact multi-band antennas.

Fractals are known as infinitely complex because of its similarity at all levels of magnification [4]. There are only two types of fractals, natural fractals and mathematical fractals. Fractal geometries can be observed all around us in our daily life, even though we are not aware of that, these are the natural fractals. Examples of natural fractals are: coastlines, lightning, earthquakes, plants, vegetables, rivers, clouds, galaxies all these examples have fractal geometry. The mathematical fractal geometry has been known for a century and these are based in equations that undergo iterative process. Examples of these mathematical structures are: von Koch snowflake, the Mandelbrot set, Sierpinski carpet, the Lorenz attractor, and the Minkowski curve. Here we are using sierpinski carpet fractal concept and the antenna is designed up to third iteration.

\section{ANTENNA DESIGN}

In order to obtain multiband characteristics and good performance fractal concept is applied to microstrip antenna. In this work, sierpinski fractal geometry is applied to microstrip antenna.

The Sierpinski carpet, also known as Sierpinski gasket was named after the Polish mathematician Sierpinski who described its main properties in 1916[5]. It is generated according to the IFS method. A rectangular elementary shape is iteratively shaped, rotated and translated, then removed from the original shape in order to generate a fractal.

The multiband microstrip antenna design starts by designing a rectangular microstrip antenna. A rectangular microstrip antenna is designed using RogersRT/Duroid substrate of height $0.794 \mathrm{~mm}$ and relative permittivity of 2.2 . The length and width of the microstrip are calculated using formulas from antenna theory text book[1].The location of microstrip feed to the patch is adjusted to match with its input impedance (usually $50 \mathrm{ohm}$ ). In this paper microstrip antenna with both edge feeding and inset feeding techniques are designed for a resonant frequency of $7.4 \mathrm{GHz}$. The dimensions of microstrip antennas are as follows,

\section{Design Considerations}

- Dielectric substrate $\varepsilon_{r}=2.2$

- Substrate height $=0.794 \mathrm{~mm}$

- Frequency $f_{0}=7.4 \mathrm{GHz}$

- $W=\frac{c}{2 f_{0}} \sqrt{\frac{2}{\varepsilon_{r}+1}}=16 \mathrm{~mm}$

- $\varepsilon_{\text {reff }}=\frac{\varepsilon_{r}+1}{2}+\frac{\varepsilon_{r}-1}{2}\left[1+12 \frac{h}{W}\right]^{-\frac{1}{2}}=2.075$

$$
\begin{aligned}
& \Delta L=0.412 h \frac{\varepsilon_{\text {reff }}+0.3\left(\frac{W}{h}+0.264\right)}{\varepsilon_{\text {reff }}+0.258\left(\frac{W}{h}+0.8\right)}=0.732 \mathrm{~mm} \\
& -L_{e f f}=\frac{c}{2 f_{0} \sqrt{\varepsilon_{\text {reff }}}}=14.1 \mathrm{~mm} \\
& -\quad L=L_{\text {eff }}-2 \Delta L=13.2 \mathrm{~mm}
\end{aligned}
$$

\section{SIMULATION RESULTS}

The microstrip antenna with microstrip feed and inset feed are designed using ANSOFT HFSS by using the above formulas and the designed antennas are as shown Figure.1(a) and (b) respectively and the S11 graph for both microstrip feed and inset feed are as shown in Figure.2

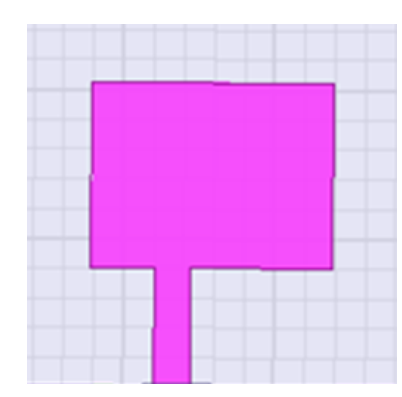

(a)

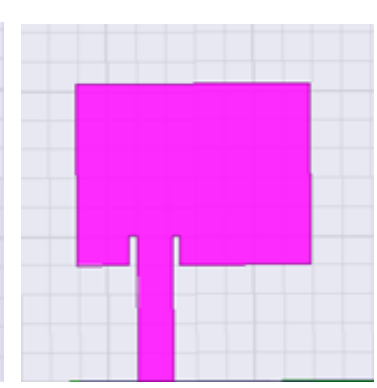

(b)
Fig 1 (a) Microstrip antenna with microstrip feed (b) Microstrip antenna with inset feed

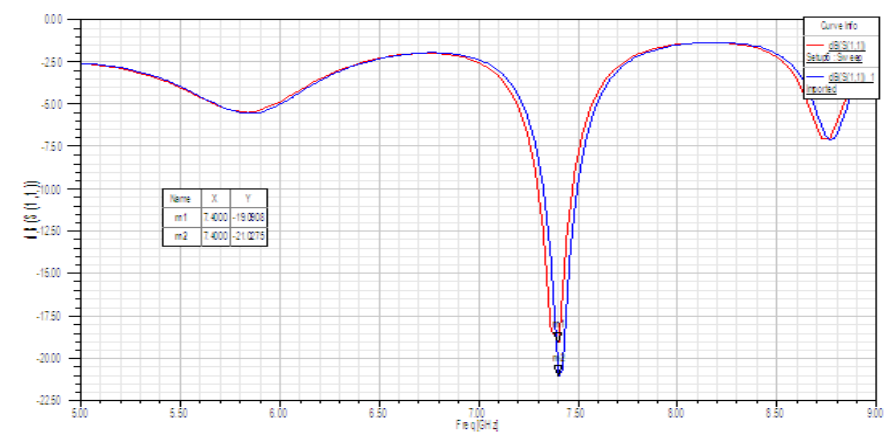

Fig.2 S11 graph for both edge feed and inset feed Microstrip antennas.

In order obtain multiband characteristics sierpinski carpet fractal (SCF) concept is applied to microstrip antenna.The first iteration is obtained by removing $1 / 3^{\text {rd }}$ slot from centre of the patch, the second iteration is obtained by removing $1 / 3^{\text {rd }}$ dimension of first slot and the third iteration is obtained by removing $1 / 3^{\text {rd }}$ dimension of slot in second iteration and edge feeding, inset feeding are applied, and they are shown in Figure. $3 \& 4$ respectively. 


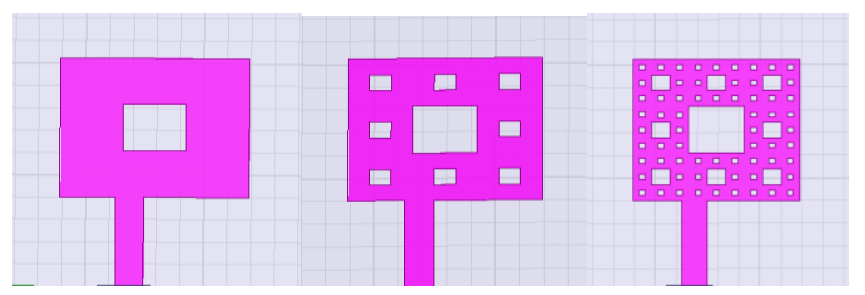

(a)

(b)

(c)

Fig.3 (a)Microstrip antenna with SCF concept for microstrip feed $1^{\text {st }}$ iteration(b) $2^{\text {nd }}$ iteration(c) $3^{\text {rd }}$ iteration.

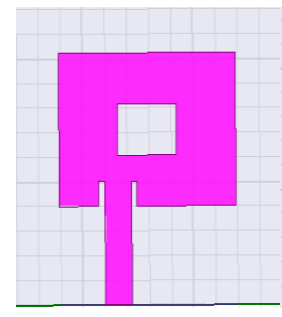

(a)

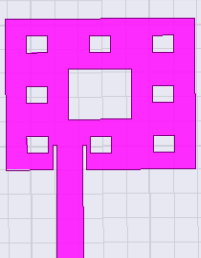

(b)

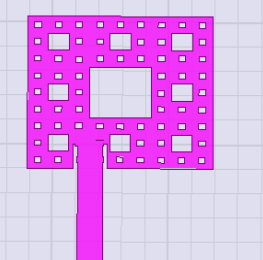

(c)
Fig.4 (a) Microstrip antenna with SCF concept for inset feed $1^{\text {st }}$ iteration $(b) 2^{\text {nd }}$ iteration (c) $3^{\text {rd }}$ iteration

The S11 graph for first iteration with microstrip feed and inset feed are as shown in Figure.5 and Figure.6 respectively.

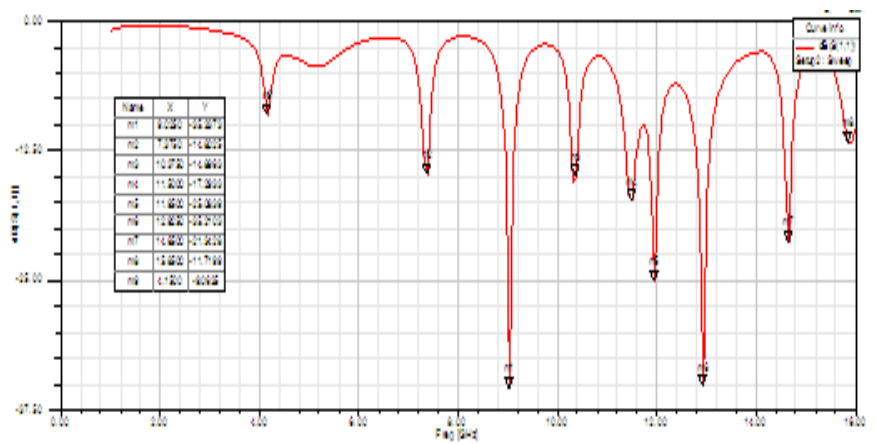

Fig.5 S11 graph for $1^{\text {st }}$ iteration edge fed antenna

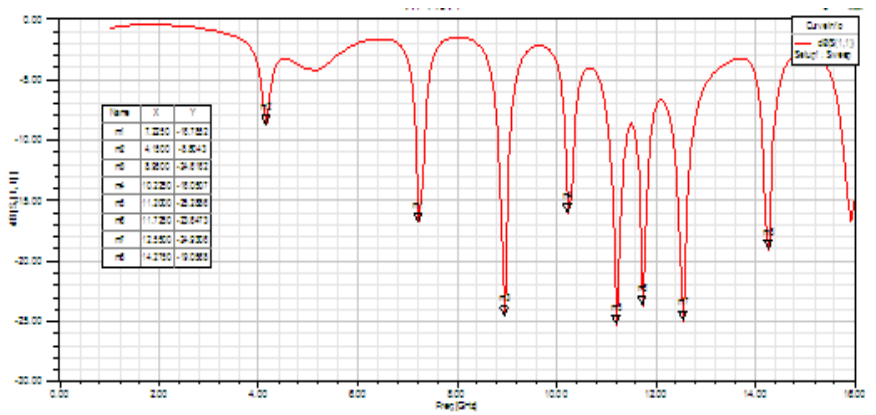

Fig $6 \mathrm{~S} 11$ graph for $1^{\text {st }}$ iteration inset fed antenna
The S11 graph for second iteration with microstrip feed and inset feed are as shown in Figure.7 and Figure.8 respectively.

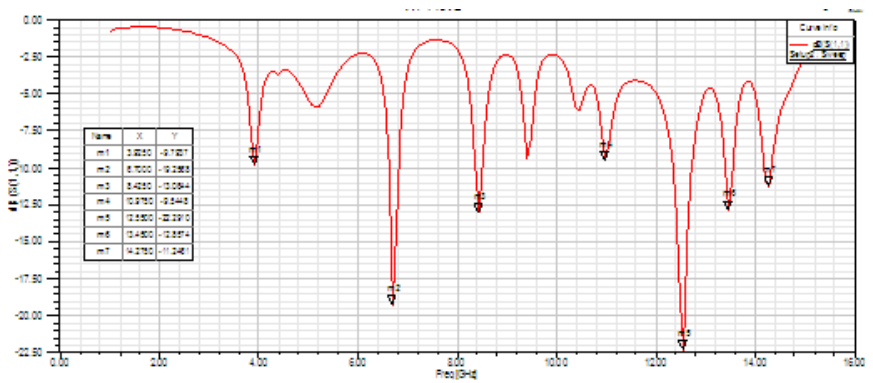

Fig $7 \mathrm{~S} 11$ graph for $2^{\text {nd }}$ iteration edge fed antenna

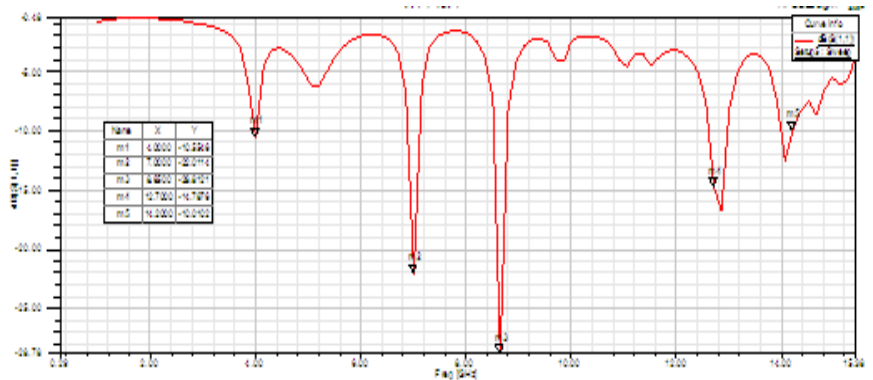

Fig $8 \mathrm{~S} 11$ graph for $2^{\text {nd }}$ iteration inset fed antenna

The S11 graph for third iteration with microstrip feed and inset feed are as shown in Figure.9 and Figure.10 respectively.

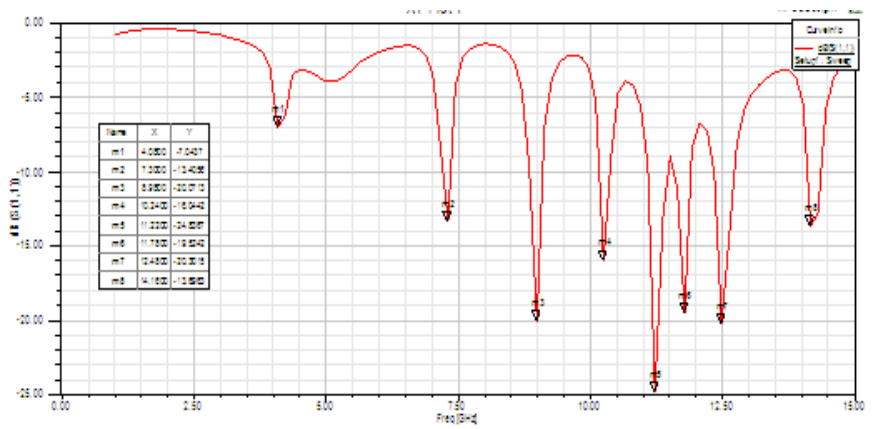

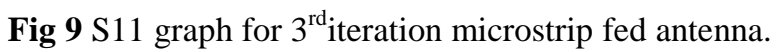

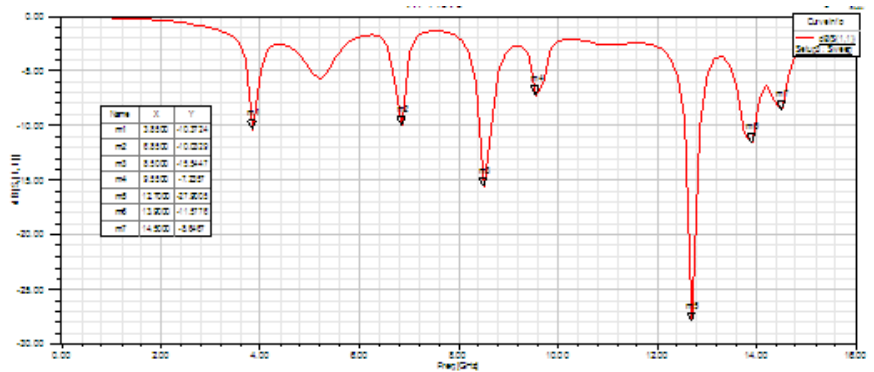

Fig 10 S11 graph for $3^{\text {rd }}$ iteration inset feed antenna. 
Table 1: Simulated results for edge feed

\begin{tabular}{|c|c|c|}
\hline Iteration & Frequency bands(GHz) & Gain $(\mathrm{dB})$ \\
\hline $\begin{array}{c}\text { Microstrip } \\
\text { antenna }\end{array}$ & 7.4 & 2.6 \\
\hline $1^{\text {st }}$ & $\begin{array}{c}6.6,8.3,9.1,10.3,12.5,13.4, \\
14.2\end{array}$ & 3.4 \\
\hline $2^{\text {nd }}$ & $\begin{array}{c}4.1,6.9,8.6,12.6,14.1 \\
\text { rd }\end{array}$ & 4.1 \\
\hline $3^{\text {rd }}$ & $\begin{array}{c}3.8,6.8,8.5,9.5,12.7,13.9, \\
14.5\end{array}$ & 4.4 \\
\hline
\end{tabular}

Table 2: Simulated results for inset feed

\begin{tabular}{|c|c|c|}
\hline Iteration & Frequency bands $(\mathrm{GHz})$ & Gain $(\mathrm{dB})$ \\
\hline $\begin{array}{c}\text { Microstrip } \\
\text { antenna }\end{array}$ & 7.4 & 2.2 \\
\hline $1^{\text {st }}$ & $\begin{array}{c}4.1,7.3,9.1,10.3,11.9,12.9, \\
14.6\end{array}$ & 2.9 \\
\hline $2^{\text {nd }}$ & $\begin{array}{c}4.2,7.2,8.9,10.2,11.2,12.5, \\
14.2\end{array}$ & 3.2 \\
\hline $3^{\text {rd }}$ & $\begin{array}{c}4.0,7.3,8.9,10.2,11.2,11.8, \\
12.4,14.1\end{array}$ & 3.7 \\
\hline
\end{tabular}

\section{CONCLUSIONS}

In this paper, a multiband microstrip antenna is designed by applying sierpinski carpet fractal concept to microstrip antenna. The antenna is designed both for edge feeding and inset feeding techniques up to $3^{\text {rd }}$ iteration with a scale factor of $1 / 3$. From the results, we can observe that by applying fractal concept to microstrip antenna, the antenna can be operated in multiple bands and as the number of iterations increased, the gain of the antenna is improved. By comparing the results, for edge feed antenna and inset feed antenna, inset fed antenna gives more gain. The size of microstrip patch is also reduced to $33.9 \%$ of conventional microstrip antenna.

\section{REFERENCES}

[1] C.A.Balanis, "Antenna Theory - Analysis and Design", 2nd edition, John Wiley \& Sons Inc., 1997.

[2] Rahul Batra and Prof. P. L. Zade, "Design of Sierpinski Carpet Fractal Antenna for Wireless Communication", International Conference on VLSI,Communication and Networks (VCAN-2011), Alwar, Rajasthan, India.

[3] Howell, J. Q.,Microstrip Antennas, “ IEEE Trans.Antennas Propagation, Vol. AP-23, January 1975, pp.90-93

[4] Werner, D. H. and S. Ganguly, "An overview of fractal antenna engineering research," IEEE Antennas and Propagation Magazine, Vol.45, No. 1, 38-57, 2003.

[5] C. Puente, J. Romeu, R. Pous, and A. Cardama, "On the behavior of the Sierpinski multiband fractal antenna," IEEE Trans. Antennas Propagat.,vol. 46, pp. 517-524, Apr. 1998. 